\title{
PMDB Masyarakat Tanggap Sampah Melalui Teknologi Biopori Di Kota Tebing Tinggi
}

\author{
Amrizal1, Indra Fauzi ${ }^{2}$, Fadli ${ }^{3}$, Samiran ${ }^{4}$ \\ 1,2,3,4Politeknik Negeri Medan \\ email: ${ }^{1}$ amrizal@polmed.ac.id, 2indrafauzi@polmed.ac.id, 3 fadli@polmed.ac.id, \\ ${ }^{4}$ samiran@polmed.ac.id
}

\begin{abstract}
Abstrak
Ada lima kecamatan di Kota Tebing Tinggi pada musim hujan airnya sering tergenang- genang, artinya daya serap tanahnya kurang. Semakin berkurangnya jumlah tanah kosong dan semakin padatnya bangunan-bangunan, hal itu semua akan menyebabkan ketidakseimbangan harmoni alam, yang berakibat banjir, ditambah juga kurangnya lahan pertamanan serta area terbuka hijau. Untuk itu perlu di buat solusi berupa lubang biopori guna mengurangi dampak akibat air tergenang. Kegiatan pengabdian kepada masyarakat ditujukan untuk problem solving komprehensif dan bermakna, tuntas dan berkelanjutan. Pelaksanaan Pengabdian Masyarakat Desa Binaan yaitu kerja sama antara Politeknik Negeri Medan dengan Dinas Perumahan, Kawasan Permukiman dan Kebersihan Kota Tebing Tinggi, yaitu berupa pembuatan 1.000 lubang biopori di halaman rumah, sekitar pepohonan, sekitar tempat parkir dan tempat terbuka lainnya. Tujuan dari pemasangan Biopori ini adalah memaksimalkan air yang meresap ke dalam tanah, membuat kompos alami dari sampah organic, mengurangi genangan air yang menimbulkan penyakit, mengurangi air hujan yang dibuang percuma ke laut, mengurangi resiko banjir di musim hujan, dan memaksimalisasi peran dan aktivitas flora dan fauna tanah. Pelaksanaan kegiatan telah dilakukan sejak bulan Nopember sampai Desember 2019 yang dilaksanakan oleh Tim UPPM Polmed yang terdiri dari 4 orang. Pada kegiatan ini berhasil dibuat 1.000 lubang di 11 kelurahan di Kota Tebing Tinggi. Kendala pembuatan biopori yaitu lahan yang ditimbuni dengan batu dan tanah yang keras sehingga kesulitan ketika dilakukan pengeboran, kendala kedua yaitu kegiatan yang dilakukan pada saat musim penghujan menyebabkan lahan banyak yang tergenang air bahkan terjadi banjir sehingga menambah waktu pengerjaan menjadi semakin panjang. pada masa mendatang kegiatan ini dapat dilanjutkan dengan mitra binaan yang akan memperoleh pendampingan untuk penanganan air genangan dan drainase perkotaan di Kota Tebing Tinggi.
\end{abstract}

Kata Kunci: lubang biopori, pembuatan, Kota Tebing Tinggi

\section{Abstract}

There are five sub-districts in Tebing Tinggi City in the rainy season is often inunlit, meaning that the soil absorbent power is lacking. The reduced number of vacant land and the more crowded buildings, it will all cause an imbalance of natural harmony, which resulted in 


\section{JURNAL ABDIMAS BSI}

Jurnal Pengabdian Kepada Masyarakat

flooding, plus also the lack of landscaping and green open areas. Therefore, it is necessary to make a solution in the form of biopori holes to reduce the impact of flooded water. Community dedication activities are aimed at solving comprehensive and meaningful, complete and sustainable problems. Implementation of Community dedication, cooperation between Medan State Polytechnic and the Department of Housing, residential area and high cliff city cleanliness, namely the manufacture of 1,000 biopori holes in the yard of the house, around the trees, Around the parking lot and other open areas. The goal of this Biopori installation is to maximize the water that permeates into the soil, make natural compost from organic waste, reduce the puddle of the disease, reduce the rain that is discharged free into the sea, reduce the risk of flooding in The rainy season, and maximizes the role and activity of soil flora and fauna. The implementation of activities has been conducted from November to December 2019 conducted by Team UPPM Polmed consisting of 4 people. In this activity, there were 1,000 holes in 11 villages in Tebing Tinggi City. The constraints of making Biopori is the land that is caused by stone and hard soil so that difficulties when done drilling, the second obstacle is the activity that is done during the rainy season caused many land that flooded water even Flooding occurs, which increases the longer working time. In the future this activity can be continued with the target partners who will receive assistance for water handling of puddle and urban drainage in Tebing Tinggi.

Keywords: biopori hole, manufacture, Tebing Tinggi city

\section{Pendahuluan}

Kota Tebing Tinggi berjarak lebih kurang $78 \mathrm{~km}$ dari Medan. Ada lima kecamatan di Kota Tebing Tinggi pada musim hujan airnya sering tergenang- genang, artinya daya serap tanahnya kurang. Semakin berkurangnya jumlah tanah kosong dan semakin padatnya bangunan-bangunan, hal itu semua akan menyebabkan ketidakseimbangan harmoni alam, yang berakibat banjir, ditambah juga kurangnya lahan pertamanan serta area terbuka hijau (DR. BOYKE SETIAWAN, 2014). Untuk itu perlu di buat solusi berupa lubang biopori guna mengurangi dampak akibat air tergenang.

Lubang biopori merupakan teknologi sederhana untuk konservasi lahan dan penyediaan air bersih (Hakim, 2016). Lubang ini dikembangkan atas dasar prinsip ekohidrologis, yaitu memperbaiki kondisi ekosistem tanah untuk perbaikan fungsi hidrologis ekosistem tersebut (Hakim, 2016). Teknologi ini bisa diaplikasikan di kawasan perumahan yang $100 \%$ kedap air atau sama sekali tidak ada tanah terbuka maupun di areal persawahan yang berlokasi di kawasan perbukitan (Hayati, 2011).

Lubang biopori berfungsi untuk meresapkan air ke dalam tanah dan dapat digunakan untuk membuat kompos. Lubang biopori tidak membutuhkan area yang luas dan proses pembuatannya sangat mudah, hal ini tentu menjadi solusi yang tepat untuk wilayah dengan lahan terbuka yang sempit(Karuniastuti, 2014).

Mengacu kepada kondisi di atas, melihat kontur Kota Tebing Tinggi boleh dikatakan rata tidak ada perbukitan, Dinas Perumahan, Kawasan Permukiman dan Kebersihan sebagai Mitra menyampaikan permasalahan yaitu pada musim hujan di Kota Tebing Tinggi banyak terdapat genangan air dikarenakan daya serap air ke dalam tanah 
sangat kurang. Untuk mengatasi hal tersebut perlu dicari solusinya berupa pembuatan lubang biopori di beberapa kecamatan di Kota Tebing Tinggi yang sering tergenang air ketik musim penghujan.

\section{Lubang Biopori}

Biopori adalah teknologi alternatif dan sederhana untuk penyerapan air hujan selain dengan sumur resapan. Istilah keren untuk biopori adalah istana cacing, walaupun sebenarnya penghuni biopori bukan hanya cacing. Selain untuk resapan air, biopori juga berguna sebagai pengolah sampah rumah tangga yang dapat diterapkan di lahan pemukiman perkotaan yg sempit. (Imron, 2018)

\section{Cara kerja Biopori}

Sampah organik yang dimasukan ke dalam lubang yang telah dibuat akan memicu biota tanah seperti cacing, semut, dan akar tanaman untuk membuat rongga-rongga. Rongga-rongga tersebut akan menjadi jalur bagi air untuk meresap ke dalam tanah. (Iqbal, 2019)

\section{Pemeliharaan biopori (Kumtus.com, 2015)}

Agar biopori yang telah dibuat bisa bertahan lama, maka ada beberapa yang harus anda lakukan untuk memelihara kondisi biopori, diantaranya adalah:

1. Lubang Resapan Biopori harus selalu terisi sampah organik

2. Sampah organik dapur bisa diambil sebagai kompos setelah dua minggu, sementara sampah kebun setelah dua bulan. Lama Pembuatan kompos juga tergantung jenis tanah tempat pembuatan Lubang Resapan Biopori, tanah lempung agak lebih lama proses kehancurannya. Pengambilan dilakukan dengan alat bor.

Manfaat Biopori (Anonim, 2018)

Pembuatan biopori juga memiliki tujuan agar kita memperoleh manfaat. Berikut ini ada empat manfaat yang kita dapatkan jika membuat lubang resapan biopori di halaman rumah.

\section{Mengurangi Sampah Organik}

Pembuatan lubang resapan biopori dapat mengurangi sampah organik dari rumah kita ke TPA (Tempat Pembuangan Akhir). Karena, ketika kita membuat lubang, salah satu proses yang harus dilakukan adalah memasukkan sampah organik.

Selain mengurangi sampah organik yang akan dibuang ke TPA, pembuatan biopori juga akan membuat masyarakat biasa memilah antara sampah organik dan anorganik.

\section{Menyuburkan Tanah}

Ketika kita memasukkan sampah organik ke dalam lubang, akan terjadi proses biologis yang akan menjadikan sampah tersebut menjadi pupuk kompos. Dengan terbentuknya pupuk kompos di dalam lubang, tentu akan membuat tanah menjadi lebih subur. 


\section{Membantu Mencegah Terjadinya Banjir}

Saat ini, banjir sering terjadi entah itu di kota atau di kampung, dan salah satu penyebabnya adalah sistem drainase yang tidak baik. Biasanya di daerah padat penduduk drainasenya buruk karena kurangnya daya serap air oleh tanah.

Dengan membuat lubang resapan biopori, dapat membantu air untuk segera masuk ke dalam tanah. Selain itu, sampah organik yang ada di dalam lubang merupakan makanan dari cacing tanah.

Cacing yang masuk ke dalam lubang akan membuat terowongan-terowongan kecil di dalam tanah ketika menuju ke lubang yang berisi sampah organik. Hal ini tentu akan membuat air lebih cepat meresap ke dalam tanah.

\section{Mempengaruhi Jumlah Air Tanah}

Terowongan-terowongan kecil yang dibuat oleh cacing tanah akan meningkatkan luas permukaan tanah. Hal ini tentu akan membuat kapasitas tanah untuk menampung air menjadi meningkat. Bahkan, lubang resapan biopori ini mampu meningkatkan luas bidang resapan menjadi 40 kali lipat.

Langkah-langkah Pembuatan Biopori (Anonim, 2018)

1. Tentukan lokasi pembuatan biopori.

2. Siram tanah atau tempat yang dipilih dengan air agar tanah jadi lebih lunak sehingga lebih mudah unutk dilubangi.

3. Lubangi tanah menggunakan bor tanah, buat lubangnya diusahakan yang tegak lurus ya.

4. Lubang yang dibuat kedalamannya kurang lebih 1 meter dengan diameter 10-30 $\mathrm{cm}$.

5. Lapisi lubang menggunakan pipa PVC yang punya ukuran sesuai dengan diameter lubang.

6. Semen sedikit bagian di sekitar mulut lubang agar lebih kuat.

7. Isi lubang biopori dengan sampah organik, bisa daun, rumput, kulit buah, atau sampah lain yang berasal dari tanaman.

8. Terakhir, tutup lubang menggunakan kawat besi. Atau, kamu jgua bisa pakai tutup pipa PVC yang sudah dilubangi terlebih dahulu.

\section{Metode Pelaksanaan Kegiatan}

Rencana Metode Pelaksanaan kegiatan (tahapan atau langkah-langkah) dalam melaksanakan solusi yang ditawarkan untuk mengatasi permasalahan sebagai berikut:

1. Melakukan survei ke lokasi tentang permasalahan mitra yaitu Dinas Perumahan, Kawasan Pemukiman dan Kebersihan Kota Tebing Tinggi Propinsi Sumatera Utara.

2. Mengumpulkan dan mendata permasalahan berupa terjadinya genangan air di waktu musim penghujan serta menentukan skala prioritas terkait kawasan yang akan dapat dilakukan kegiatan Pengabdian Masyarakat Desa Binaan.

3. Mencari solusi pemecahan permasalahan berupa pembuatan lubang biopori atau metode lainnya dan membuat kerjasama dengan mitra, yaitu meminta surat 
pernyataan kesediaan mitra untuk bekerja sama dalam melaksanakan program PMDB.

4. Menetapkan solusi yang akan diusulkan yaitu pembuatan lubang biopori, sesuai dengan proposal yang diajukan oleh mitra yaitu Dinas Perumahan, Kawasan Permukiman dan Kebersihan Kota Tebing Tinggi, kemudian melakukan survei harga bahan dan peralatan yang dibutuhan dan kebutuhan lain untuk didanai oleh UPPM Polmed melalui dana DIPA.

5. Melaksanakan kegiatan Pengabdian Masyarakat Desa Binaan yang terdiri dari:
a. Diawali pengarahan kepada masyarakat tentang tujuan dari pembuatan lubang biopori;
b. Setelah itu dilanjutkan dengan pembersihan lokasi;
c. Pembelian bahan-bahan dan peralatan yang diperlukan;
d. Pelaksanaan pembuatan biopori dengan memotong pipa PVC yang akan ditanam dan melubanginya;
e. Kemudian dilanjutkan dengan pembuatan lubang di lahan;
f. Penanaman pipa di lubang yang sudah dibuat;
g. Penutupan pipa dengan tutup/dob PVC yang sudah dilubangi;
h. Penyemenan tanah di sekitar tutup pipa agar pipa tidak mudah bergeser;
i. Seluruh pekerjaan ini akan dilaksanakan oleh Tim Pengabdian bersama-sama dengan masyarakat secara gotong-royong.

6. Melaksanakan serah terima hasil pekerjaan yang sudah selesai dengan masyarakat untuk dapat digunakan sebagaimana mestinya.

7. Membuat dokumentasi dari hasil pengabdian dan mempublikasi pada media masa cetak dan elektronik serta jurnal pengabdian masyarakat nasional.

8. Membuat laporan hasil pengabdian untuk dipresentasikan sebagai pertanggung jawaban kepada UPPM Politeknik Negeri Medan.

Tabel 1 Rencana Kegiatan, Evaluasi dan Indikator Luaran

\begin{tabular}{|c|c|c|}
\hline Kegiatan & Evaluasi & Indikator Luaran \\
\hline $\begin{array}{l}\text { Persiapan pengabdian, survey } \\
\text { khalayak sasaran }\end{array}$ & $\begin{array}{l}\text { Evaluasi dilakukan dengan } \\
\text { Melihat khalayak sasaran tentang } \\
\text { keberlanjutan dari program yang } \\
\text { akan diusulkan }\end{array}$ & $\begin{array}{l}\text { Proposal pengabdian, Surat } \\
\text { pernyataan dukungan kesediaan } \\
\text { kerja sama dari mitra }\end{array}$ \\
\hline $\begin{array}{l}\text { Mengidentifikasi masalah } \\
\text { utama yang dihadapi pada } \\
\text { mitra kerja sama }\end{array}$ & $\begin{array}{l}\text { Menawarkan solusi pemecahan } \\
\text { masalah }\end{array}$ & $\begin{array}{l}\text { Terlaksananya solusi yang } \\
\text { ditawarkan dalam pemecahan } \\
\text { masalah }\end{array}$ \\
\hline $\begin{array}{l}\text { Pembuatan biopori sebanyak } \\
1000 \text { lubang untuk lima } \\
\text { kecamatan di Kota Tebing } \\
\text { Tinggi }\end{array}$ & $\begin{array}{l}\text { Evaluasi dilakukan dengan } \\
\text { berkunjung ke lokasi dan } \\
\text { mengadakan tanya jawab dan } \\
\text { melihat langsung kodisi lapangan }\end{array}$ & $\begin{array}{l}\text { Sudah terlaksananya } \\
\text { Peangmasangan biopori } \\
\text { sebanyak } 1000 \text { lubang untuk } \\
\text { lima kecamatan di Kota Tebing } \\
\text { Tinggi }\end{array}$ \\
\hline
\end{tabular}

\section{Manfaat Kegiatan}

Manfaat yang diharapkan dari Pengabdian kepada Masyarakat ini adalah: 


\section{JURNAL ABDIMAS BSI}

Jurnal Pengabdian Kepada Masyarakat

1. Terpecahkannya masalah mitra, yaitu solusi yang dilaksanakan ini terbukti dengan terlaksananya program yang diusulkan.

2. Terlaksananya hubungan kerjasama mitra dengan Polmed

3. Terlaksananya indikator luaran yang direncanakan.

\section{Hasil dan Pembahasan}

Setelah dilakukan pembuatan 1.000 lubang biopori melalui Pengabdian Masyarakat Desa Binaan Politeknik Negeri Medan pada 11 Kelurahan di 5 Kecamatan Kota Tebing Tinggi yaitu:

a. Kelurahan Lalang, 150 lubang;

b. Kelurahan Mekar Sentosa, 100 lubang

c. Kelurahan Rantau Laban, 75 lubang;

d. Kelurahan Tanjung Marulak, 75 lubang;

e. Kelurahan Persiakan, 100 lubang;

f. Kelurahan Tualang, 100 lubang;

g. Kelurahan Bandar Sono, 100 lubang;

h. Kelurahan Bandar Utama, 100 lubang;

i. Kelurahan Mandailing, 100 lubang;

j. Kelurahan Tebing Tinggi, 50 lubang;

k. Kelurahan Pinang Mancung, 50 lubang.

maka dampak tergenangnya air dapat dikurangi sehingga tidak banyak lagi genangan air di lahan milik masyarakat.

Di sisi yang lain masyarakat mendapatkan pupuk kompos secara gratis dari hasil pelapukan dedauan yang dimasukkan ke dalam lubang biopori.

Evaluasi kegiatan pengabdian masyarakat ini dilakukan melalui beberapa cara, yaitu evaluasi terhadap proses dan evaluasi terhadap hasil. Evaluasi proses dapat dilihat dari keseriusan masyarakat dalam pembuatan lubang biopori bahkan rela lahan di rumahnya untuk dibuat lubang biopori.

Kendala yang terjadi di lapangan yaitu banyaknya lahan yang merupakan bekas timbunan berbagai macam material yang keras sehingga kesulitan ketika dilakukan pengeboran. Kendala lainnya yaitu kegiatan yang dilakukan bertepatan dengan musim penghujan sehingga memakan waktu yang lebih lama dari waktu yang direncanakan sebelumnya.
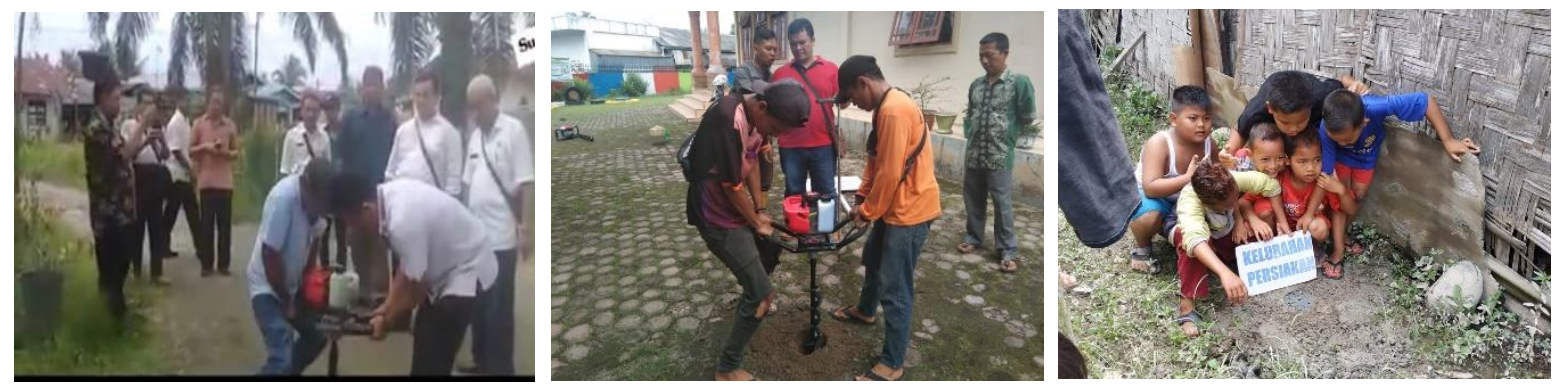

Gambar 1 Pembuatan 1.000 Lubang Biopori di 11 Kelurahan Kota Tebing Tinggi 
Kepala Dinas Perumahan, Kawasan Permukiman dan Kebersihan Kota Tebing Tinggi melalui Sekretaris Dinas Jhoni Perlindungan menyambut baik program dari Polmed, karena dengan adanya resapan biopori banjir dan genangan akan bisa dikurangi (Antara News, 2019).

Tim Pengabdian Kepada Masyarakat Polmed mengatakan kegiatan ini merupakan program pengabdian masyarakat desa binaan yang peduli tentang sampah.(Sumut Pos, 2019)

\section{Simpulan dan Rekomendasi}

1. Pelaksanaan pembuatan 1.000 lubang biopori merupakan solusi dari permasalahan genangan air yang terjadi di musim penghujan di Kota Tebing Tinggi, hal ini dapat mengurangi dampak dari genangan air tersebut disamping itu masyarakat mendapatkan pupuk kompos dari pelapukan sampah dedaunan yang dimasukkan ke dalam lubang tersebut.

2. Pembuatan lubang biopori dilakukan pada 11 kelurahan di 5 kecamatan Kota Tebing Tinggi

3. Kendala pembuatan biopori yaitu lahan yang ditimbuni dengan batu dan tanah yang keras sehingga kesulitan ketika dilakukan pengeboran, kendala kedua yaitu kegiatan yang dilakukan pada saat musim penghujan menyebabkan lahan banyak yang tergenang air bahkan terjadi banjir sehingga menambah waktu pengerjaan menjadi semakin panjang.

4. Memperhatikan sangat bermanfaatnya kegiatan pembuatan lubang biopori guna mengurangi dampak akibat genangan air di Kota Tebing Tinggi maka sangat diperlukan kegiatan ini untuk dilanjutkan pada Tahun Depan yaitu berupa pendampingan untuk penanganan air genangan dan drainase perkotaan di Kota Tebing Tinggi.

\section{Daftar Pustaka}

Anonim. (2018). Cara Membuat Biopori untuk Resapan Air dan Mengatasi Banjir. Balai Wilayah Sungai Sulawesi II, 1.

Antara News. (2019). Politeknik Negeri Medan buat 1.000 Lobang Biopori di Tebingtinggi. Antara News, pp. 1-15.

Imron, M. (2018). Membuat Lubang Resapan Biopori. 1-11.

Iqbal, M. (2019). Rumah Sering Banjir? Simak Cara Membuat Biopori Untuk Menanggulanginya!

Karuniastuti, N. (2014). Teknologi Biopori untuk Mengurangi Banjir dan Tumpukan Sampah Organik. Jurnal Forum Teknologi.

Kumtus.com. (2015). Hasil Penelitian Karya Ilmiah Biopori.

Sumut Pos. (2019). Polmed Medan Buat 1.000 Lubang Resapan Air. Sumut Pos, pp. 17. 
dr. Boyke Setiawan, M. (2014). Program Kerja Lpm Stima Immi. Jakarta: Sekolah Tinggi Manajemen IMMI.

Hakim, D. D. (2016, April 24). https://mtsnegeribatudaa.blogspot.com/. Diambil kembali darimakalah-tata-cara-membuat-biopori.html:

https:/ / mtsnegeribatudaa.blogspot.com/2016/04/makalah-tata-caramembuat-biopori.html

Hayati, R. S. (2011, June 10). oryza-sativa135rsh.blogspot.com. Diambil kembali dari oryza-sativa135rsh.blogspot.com: https:/ / oryzasativa135rsh.blogspot.com/2011/06/teknologi-biopori-sebagai-alternatif.html 